\title{
Whispering In: Real-time Coaching for Medical Students Rotating Virtually in Psychiatry Clinic
}

\author{
Aaron Owen ${ }^{1}$ (D) \\ Received: 29 November 2020 / Accepted: 18 February 2021 / Published online: 4 March 2021 \\ (C) Academic Psychiatry 2021
}

To the Editor:

In clinical settings, we traditionally expect the most novice (usually a medical student) to begin the interview and then hand it over to the senior if there is any hesitation. Taking over an interview in this way can feel evaluative to the learner and also is less effective because any feedback then has to be given after the patient interaction has ended. What if we instead observe the student's process and unobtrusively provide feedback that allows them to correct their own path during the interview itself?

Real-time coaching is a technique within teacher training that is possible with recent technological advances that allow the use of a wireless earpiece to give moment-to-moment feedback [1]. A coach "whispers in" the ear of the trainee as they deliver a lesson so that the feedback is immediately available for the trainee to course correct. Ample research shows that feedback is most effective if provided immediately and applied during the task [2-4]. This technique is perfectly suited to teaching within psychiatry when the patient interactions involve telehealth.

During COVID-19, I have seen patients over video from my home office, joined frequently by medical students participating in clinical rotations from physically distant locations. We meet in a virtual "room" to conduct the appointment, and after introductions and permissions, I prompt the student to begin the interview. This interaction might then proceed as normal (i.e., with the student collecting interval history and checklist review of systems until they stall), if not for the simple fact that I am simultaneously guiding the student using a secure chat text messaging function within the electronic health record. All that is required is that the student has the ability to view both the video and the chat box simultaneously.

Aaron Owen

aowen@uwhealth.org

1 University of Wisconsin Hospitals and Clinics, Madison, WI, USA
In a typical exchange over chat during an interview, I guide the student to reword a question, to inquire into specific symptoms, or to reflect the patient's emotion. I also praise effective interviewing technique. In one case, I was seeing four consecutive patients with a student who had been rotating with various providers in the outpatient psychiatry clinic for about a week. The student said she was comfortable leading the initial interview, and I explained that I would refrain from interrupting by sending pertinent chat messages for her reference during the process. Here is a composite transcript simulating the dialogue (for example, midway through the first medication management appointment, at a point when the student began asking somewhat repetitive yes/no questions):

Medical Student: So, the change to clomipramine has been good?

Patient: I think so.

Me via Chat: [Ask how it has been good; open-ended]

Medical Student: How has the change been helpful?

Patient: Well, I feel like the anxiety is a huge difference.

I have only been calling my mom once a day, and if she doesn't answer I will just leave a voicemail instead of calling over and over. I think I didn't realize how much it was affecting my life.

Medical Student: OK, so it sounds like the OCD is under better control?

Patient: For sure.

Me via Chat: [Try "What are you hoping to discuss to make this a helpful meeting?"]

Medical Student: What would make today's appointment helpful?

Patient: Well, I guess I am wondering if I can go up anymore on the clomipramine, because I think it is helping, but my concern is that I know there can be side effects.

The student had not explicitly included the patient in agenda setting at the outset of the appointment, and by giving this 
prompt, the student was able to regain the momentum of the interview. Providing the struggling student with some new tools that were immediately applicable allowed the interview to proceed smoothly with the student at the helm. The student was even able to give appropriate anticipatory guidance to the patient based on information we exchanged in the chat throughout the interview. At the end, I concluded the interview by restating the plan with specific dosing instructions and precautions, but very little was new information that the student had not included already.

By the second and third appointments, the student was more relaxed and conversational while also requiring less directive feedback to guide the interview in a purposeful arc. The final appointment was with a particularly challenging patient who typically presents in a crisis requesting medication adjustments. This is not an appointment I would normally ask a student to lead. However, the student said she felt comfortable attempting the interview given the added support of the real-time coaching, as in this composite example:

Medical Student: What's on your mind today?

Patient: Well, my meds aren't working because I'm just overwhelmed with the state of the world and the absolute lack of decency! (Patient begins to cry)

Medical Student: I'm so sorry to hear things are not going well.

Patient: Well, at least you care. (Smiling slightly)

Me via Chat: [Try to keep the interview emotionally

neutral. "What's a typical day like?"]

Student: How do you spend a normal day?

The students have reflected feeling more supported and less flustered when receiving real-time coaching. Consistent with other others' experience, the students have found the feedback to be formative and positive [5]. Students in general do not become dependent on real-time coaching, and when possible, they default back to running the interview independently. This student in particular said "I normally get caught up more in my own info than what is going on with the patient, and having you redirecting me kept the conversation going."

By taking advantage of the technological innovations that make telehealth possible, we can also increase our effectiveness as "tele-teachers." Our feedback can be used in real-time to promote rapid improvement and active participation. Rather than focus on what a student did or did not do (evaluative), we can give them the tools they need as the need comes up (instructive). Bolstering the student's engagement and sense of efficacy is also vital to recruiting students into our field.

Acknowledgements The author thanks Laurel Bessey, M.D., Marc Kalin, D.O., and Steven Garlow, M.D., Ph.D., for their guidance, helpful review, and comments.

\section{Declarations}

Disclosures The author states that there is no conflict of interest.

\section{References}

1. Sharplin E, Stahl G, Kehrwald BA. It's about improving my practice: learner experience of Real-Time Coaching. Aust J Teach Educ. 2016;41(5):119-35.

2. Hattie J, Timperley H. The power of feedback. Rev Educ Res. 2007;77:81-112.

3. Kulik J, Kulik C. Timing of feedback and verbal learning. Rev Educ Res. 1988;58:79-97.

4. Schroth M, Lund E. Role of delay of feedback on subsequent pattern recognition transfer tasks. Contemp Educ Psychol. 1993;18:15-22.

5. Vergara-Torres A, Rodriguez J, López-Walle J, et al. Students' perceptions of teachers' corrective feedback, basic psychological needs and subjective vitality: a multilevel approach. Front Psychol. 2020;11:558954.

Publisher's Note Springer Nature remains neutral with regard to jurisdictional claims in published maps and institutional affiliations. 